\title{
San Agustín educador
}

\author{
(II Settimana Agostiniana, Pavía 16-24 aprile 1970.)
}

La Semana Agustiniana de Pavía se afirma. Lo ha demostrado la segunda manifestación de la misma y el fruto que ha presentado ya de la primera. Se trata de las Actas de la I Semana Agustiniana que llevan por título L'itinerario della fede in S. Agostino. Pavía 1969. Sus páginas densas y bien presentadas son el fruto de los diversos actos habidos y de las conferencias mantenidas. Los estudiosos de San Agustín hallarán en las mismas puntos importantes de referencia.

En cuanto a la II Semana el tema no podía ser más prometedor. Y la actualidad del mismo era índice y garantía. El P. Dante Scanavino, secretario activísimo de esas jornadas, decía en una entrevista a un periódico local que «el motivo de fondo que debe inspirar cada semana agustiniana es siempre el muy práctico de hacer conocer mejor el pensamiento agustiniano para un influjo benéfico sobre la vida cristiana: los grandes maestros del cristianismo - proseguía - no se oscurecen nunca. La elección específica del tema pedagógico está determinada por una exigencia de actualidad». Como se ve ha sido la actualidad del tema la que ha inducido a tratarlo en esta Semana. Los oradores, conocidos en los ambientes agustinológicos, podían brindar - y brindaron de hecho- sabrosas conclusiones.

El Card. Garrone en su alocución en la misa de apertura de la Semana trazó los rasgos fundamentales de la figura de San Agustín como educador, haciendo resaltar su interés para el presente, dado que ha descubierto la dignidad de la persona humana del alumno y lo ha elevado a categoría. Insistió en el amor apasionado de Agustín por la verdad, verdad que venía identificada por el Santo con Cristo, y en Agustín maestro de interioridad. Su espléndida homilía, que veremos publicada en las Actas, está henchida del calor y de la inteligencia del Eminentísimo Cardenal que sabe de esas navegaciones difíciles.

Las conferencias estaban anunciadas por este orden: El día 20 de abril, Rvdmo. P. Agostino Trapè, Prior General de los Agustinos: L'azione educatrice di S. Agostino; el día 21, el prof. Alfonsi, Ordinario de Literatura Latina en la Universidad de Pavía: S. Agostino e i metodi educativi dell'antichità; el día 22, el P. Antonio Lombardi, Provincial de los Agustinos de la Provincia Romana 
disertó sobre: Funzione del maestro umano e del Maestro interiore nella educazione; el día 23 el prof. Mons. Giulio Oggioni, de la Facultad teológica de Venegono pronunciaba su conferencia sobre el tema: I problemi dll'educazione religiosa: la ricerca del metodo didattico; y el día 24 finalizaba el prof. Aldo Agazzi, Ordinario de Pedagogía en la Universidad Católica de Milán, con: L'attualità della dottrina pedagogica di S. Agostino. Los profesores, en su mayor parte, son conocidos por sus trabajos sobre temas afines en la doctrina y en la obra de San Agustín. Aunque sus relaciones no fueran más que una síntesis apretada de sus estudios extensos serían ya para el gran público una adaptación y un principio de inteligencia.

Presentar cada una de las conferencias nos llevaría demasiado lejos. E1 tema se brinda para ello. Las novedades no han sido muchas, pero los aciertos y las conclusiones ponen de manifiesto una vez más la inagotable vena del pensamiento agustiniano. Hay en las diferentes ponencias y en las homilías que mezclaban sus notas con lo científico, una doble línea fácilmente apreciable: por una parte, insisten todos — quizá sea uno de los defectos- en la carrera didáctica de Agustín, es decir, en su vocación para la enseñanza desde sus primeros años de profesor hasta su cátedra de retótica en Milán, lo cual le preparaba para sus años posteriores de sacerdote y de obispo; y por otra, en la instrumentalidad y provisionalidad del maestro humano, dejando al alumno ante su propia intimidad a la escucha del único verdadero Maestro interior, que es Cristo, que habla por la verdad. Aunque no se pusiera de relieve más que esta última afirmación, se daría por bien empleada la Semana. Es admirable ver aflorar esta conclusión desde enfoque y entronque diferentes. Si el profesor Alfonsi, fundado en Marrou, analiza los métodos educativos de la antigüedad y llega a descubrir el método agustiniano, que pretende llevar al alumno al descubrimiento por sí mismo de la verdad, excitando en él la curiosidad, consciente de que, como dirá Agustín en las Confesiones, sirve más para aprender la libre curiosidad que la obligada necesidad, los demás conferenciantes, examinando otras perspectivas, convergen en la dignidad de la persona y en el respeto máximo que Agustín garantiza al alumno. Posiblemente una de las grandes contribuciones del método agustiniano para el presente sea ésta: el hombre como maestro tiene una función que es la creación de la inquietud en el alumno y la inquietud le presentará la necesidad de buscar una solución apropiada a través de la ciencia y de la experiencia y de la vivencia. Lo que sucede con frecuencia es que la dirección agustiniana, que es general en toda su temática, no quiere llevarse a realización, porque se piensa que el hombre se descarriará, dejado a su libertad e iniciativa. Indudablemente el método personalista e intimista agustiniano tiene todavía hoy una gran vigencia y una muy nutrida audiencia.

La II Semana Agustiniana de Pavía ha sido un éxito y lo continuará siendo. La unión que ahora se ha hecho ya efectiva entre los diferentes niveles de la 
pequeña ciudad lombarda es promesa y signo de perennidad. Mientras existan unos hombres entregados a lo agustiniano y un secretario que como el P. Dante Scanavino aliente esa empresa, podemos estar seguros de que la periodicidad de estos encuentros producirán frutos abundantes. De esta suerte Pavía volverá a ser un gran monumento viviente a la memoria nunca olvidada del Obispo de Hipona.

JosÉ MoRÁN 